\title{
Percutaneous Balloon Mitral Valvuloplasty in the Elderly
}

\author{
Mahmoud Sharaf, MD*, Lotfy H. Abodahab, MD, Mohamed Bahaa, MD \\ Department of Cardiology, Sohag University Hospital, Sohag, Egypt
}

\begin{abstract}
introduction and aim of the work:-mitral stenosis still shows it self older population in developed countries.Percutaneous balloon mitral Valvuloplasty (PBMV) is the treatment of choice for severe and lor hemodynamically significant mitral stenosis. It has been developed as an alternative modality to surgical closed commissurotomy for mitral stenosis5. Elderly patients with mitral stenosis are a special entity who suffered a severe form of the disease and in the same time at higher risk of surgical mitral valve replacement, the aim of the current study is to assess and analyze clinical and echocardiographic consequences after percutaneous balloon mitral Valvuloplasty in those patients. Study design Uncontrolled prospective longitudinal single center study performed in patients referred for percutaneous balloon mitral valvuloplasty. Patients :-The current study included 40 elderly consecutive patients who underwent PBMV in Sohag university hospital cathlab unit. results and conclusion:-There was no in hospital mortality, only one patient developed severe MR , technical failure was encountered in 2 patients, because of failure of the balloon ability to traverse tight valves.This study agreed that PBMV can be applied to those with less favorable valve morphology, PBMV is a safe and effective procedure and optimal results can be achieved in patients with higher wilkin's score if they are carefully selected and operated at experienced centers.

Copyright $\odot 2017$ Science International Corp.
\end{abstract}

\section{Key Words}

Percutaneous • Mitral • Valvulopasty • Elderly

(c) 2017 Journal of Structural Heart Disease Published by Science International Corp. ISSN 2326-4004

Fax +1 2037853346

E-Mail: jshd@scienceinternational.org

http://structuralheartdisease.org/

\section{Introduction}

The prevalence of mitral stenosis is reflective of the prevalence of rheumatic fever in a particular region [1, 2]. Rheumatic valvular heart disease continues to be endemic in developing countries, with mitral stenosis being the most frequent valve disorder [3]. Although the incidence and severity of rheumatic mitral stenosis has declined in developed countries, the disease is still highly prevalent in many poor and densely populated areas of the globe, remaining a major public health issue and reflecting the socioeconomic status of the region, especially among the elderly. By contrast, mitral stenosis progresses much more rapidly in developing countries and may lead to symptoms in younger patients, including young adults, adolescents, and even children under 5 years of age in some countries [4]. However, mitral stenosis is still pervasive within older populations in developed countries.

Percutaneous balloon mitral valvuloplasty (PBMV), which was developed as an alternative to surgical closed commissurotomy [5], is the treatment of choice for severe and/or hemodynamically significant mitral stenosis. Elderly patients with mitral stenosis are a special population who suffer from a severe form of the disease and at the same time are at higher risk of surgical mitral valve replacement. Therefore, the aim of the current study was to assess the clinical and echocardiographic consequences of PBMV in elderly patients.

* Corresponding Author:

Mahmoud Sharaf, MD

Department of Cardiology

Sohag University Hospital

Elgomhoria Street Sohag, Egypt

Tel.: +20 1023620185; Fax: +20 9324602963; E-Mail: dr.m.bahaa1988@gmail.com 


\section{Materials and Methods}

\section{Study Design}

The study was an uncontrolled, prospective, longitudinal, single-center study of patients referred for PBMV. This study was approved by the Scientific Ethical Committee of Sohag Faculty of Medicine. Informed written consent was obtained from all included patients.

\section{Patients}

We recruited 40 consecutive elderly patients who underwent PBMV in Sohag University Hospital. Patients were included if they were over 60 years of age; had symptomatic moderate to severe mitral stenosis, a mitral valve area $<1.5 \mathrm{~cm}^{2}$, and no higher than grade 2/4 mitral regurgitation by echocardiography; refused to undergo surgery; and were considered high risk due to comorbid conditions (e.g., renal insufficiency, chronic pulmonary disorder, liver cirrhosis, malignancy). $\mathrm{Pa}$ tients were excluded if they met any of the following criteria: highly unfavorable mitral valve morphology (i.e., Wilkin's score $\geq 11$ ), higher than grade $2 / 4$ mitral valve regurgitation, presence of thrombus in the left atrium or left atrial appendage, presence of concomitant valve disease requiring surgical intervention, scheduled for coronary artery bypass surgery, presence of infective endocarditis, interatrial septum thickness $>4 \mathrm{~mm}$, or occurrence of cerebrovascular stroke within the previous 3 months.

\section{Procedures}

Before and 1 month after the procedure, all patients underwent clinical assessment including New York Heart Association (NYHA) functional classification, paroxysmal or persistent atrial fibrillation, history of previous PBMV or surgical commisurotomy, and history of thromboembolic events. Body mass index, sinus rhythm, atrial fibrillation, and general signs of heart failure were recorded.

Before, immediately after, and 1 month after the procedure, all patients underwent a complete two-dimensional echocardiographic study. Mitral valve area was measured by direct plannimetry of the valve orifice. From the parasternal short-axis view, the smallest area of the valve orifice obtained in early diastole was chosen for analysis. Peak and mean diastolic pressure gradients across the mitral valve were measured from Doppler spectral analysis of diastolic transmitral mitral flow in apical four-chamber view. The degree of mitral regurgitation as determined by pulsed Doppler echocardiography, color-flow Doppler echocardiography mapping, or both was graded as none (0), mild (1), moderate (2), or severe (3 or 4).

Mitral valve morphologic features were categorized according to a semi-quantitative echocardiographic score as described by Wilkin's et al. [6]. Left atrial diameter and size were measured in parasternal long- and short-axis views. Other chamber sizes and valve abnormalities were also assessed.

Transesophageal echocardiographic examination was performed immediately before the procedure using the same cardiac ultrasound machine for all patients. Assessment was performed following standard methods to exclude the presence of
Table 1. Clinical features of studied population.

\begin{tabular}{ll}
\hline Features & Statistical analysis \\
\hline Gender & \\
Females & $80 \%$ \\
Males & $20 \%$ \\
Height & \\
Mean (SD) & $159.57(8.50 \%)$ \\
Median (range) & $159(145-178 \%)$ \\
Rhythm & \\
Sinus & $75 \%$ \\
Atrial fibrillation (AF) & $25 \%$ \\
\hline
\end{tabular}

Table 2. Willkin's Score of studied population.

\begin{tabular}{ll}
\hline Features & Statistical analysis \\
\hline Thickness & \\
1 & $5 \%$ \\
2 & $45 \%$ \\
3 & $50 \%$ \\
Mobility & \\
1 & $10 \%$ \\
2 & $75 \%$ \\
3 & $15 \%$ \\
Subvalvular & \\
1 & $10 \%$ \\
2 & $50 \%$ \\
3 & $35 \%$ \\
4 & $5 \%$ \\
Calcification & \\
1 & $5 \%$ \\
2 & $50 \%$ \\
3 & $35 \%$ \\
4 & $5 \%$ \\
Total score & \\
7 & $10 \%$ \\
8 & $20 \%$ \\
9 & $40 \%$ \\
10 & $30 \%$ \\
\hline
\end{tabular}

thrombi in the left atrium or left atrial appendage and to measure mitral annular diameter and interatrial septal thickness. A blinded observer reviewed each echocardiogram.

PBMV was performed using the Inoue balloon technique. Balloon size was selected according to body surface area considering anatomy ( 1 to $2 \mathrm{~mm}$ smaller in unfavorable cases) and reached after several stepwise inflations. Hemodynamic measurements of the right and left heart, including simultaneous left atrial and left ventricular pressure recordings, were made immediately before and after valvuloplasty. PBMV was defined as successful when the Doppler mitral valve area was 


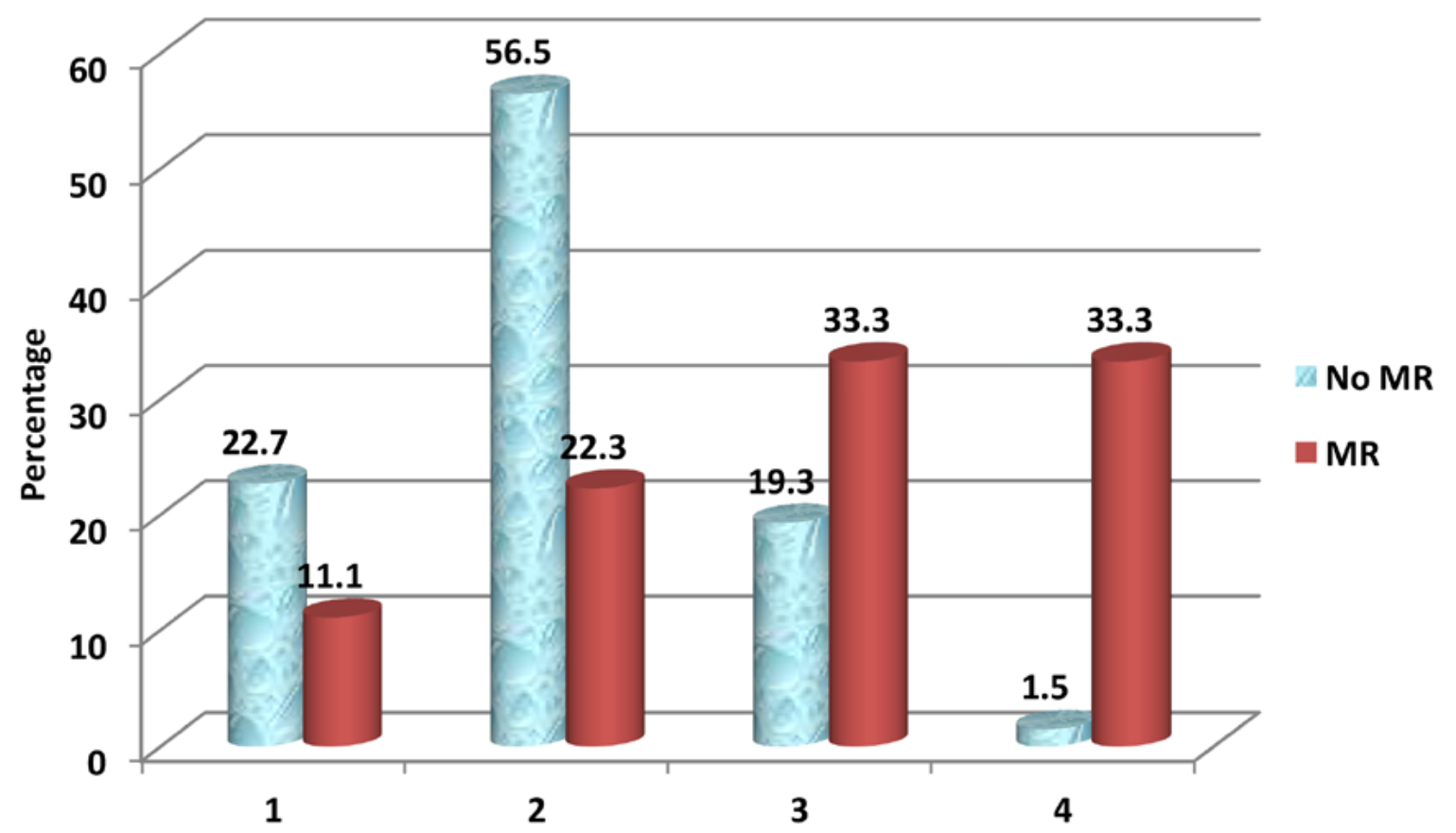

Figure 1. Comparison between those with and without MR as regard W.S. Calcification

$\geq 1.5 \mathrm{~cm}^{2}$ and there was no more than one grade increase in mitral regurgitation or no increase in gain above $50 \%$ of baseline without major complications. Major complications were defined as more than grade 2/4 mitral regurgitation, cerebrovascular stroke, cardiac tamponade, thromboembolic events, or balloon rupture with unwanted sequelae or periprocedural death.

\section{Statistical Analysis}

Data were analyzed using STATA/IC version 12.1. Quantitative data are reported as mean and standard deviation. Normally distributed or not normally distributed data were analyzed using Student's t-tests or Mann-Whitney tests, respectively. Qualitative data are reported as frequency and percentage and were analyzed using Chi-square tests or Fisher's exact tests. Statistical significance was set at $p<0.05$.

\section{Results}

\section{Pre-Operative Characteristics}

The female-to-male ratio of included patients was 4:1 (Table 1). The predominant symptom before the procedure was heart failure, which was observed in $95 \%$ of patients. Symptoms of heart failure were severe (class III or IV) in $65 \%$ of patients. A history of cerebrovascular stroke was present in one patient (2.5\%). Approximately $60 \%$ of patients were categorized as NYHA functional class III, $35 \%$ as class II, $4 \%$ as class I, and $1 \%$ as class IV.

\section{Intraoperative Events and Procedure-Related Complications}

Most patients (75\%) exhibited sinus rhythm during the procedure, whereas some patients (25\%) exhibited atrial fibrillation. Technical failure occurred in two patients due to failure of the balloon to traverse tight valves.

Non-significant increases in mitral regurgitation occurred in three patients, and one patient experienced severe mitral regurgitation that required surgical valve replacement (Table 4). Minor complications included vasovagal reaction in two patients, prolonged hypotension in one patient, and arrhythmia (i.e., multifocal ventricular ectopic beats) requiring treatment in one patient. Bleeding from the right femoral vein associated with balloon catheter insertion occurred in two patients $(5 \%)$, with neither patient requiring blood transfusion. There was no in-hospital mortality (0\%).

Mean mitral regurgitation grade increased significantly from $0.91 \pm 0.54$ before PBMV to $1.11 \pm 0.56$ post-dilatation $(p<0.01)$. Before valvuloplasty, 26 patients had no mitral regurgitation, 12 patients had grade 1, two patients had grade 2 , and no patients had grade 3 or 4 mitral regurgitation as evaluated by Doppler studies. After valvuloplasty, mitral regurgitation remained unchanged in most patients. However, the degree of mitral regurgitation increased by one grade in four patients (10\%): three increased from grade 1 to grade 2 , and one increased from grade 2 to grade 3 .

When we investigated factors associated with the development of significant mitral regurgitation (i.e., grade 2 or higher), we found a significant increase in the incidence of significant mitral regurgitation among female patients, patients with atrial fibrillation rather than sinus rhythm, and patients who un- 
Table 3. General outcomes of studied population.

\begin{tabular}{ll}
\hline Statistical analysis & \\
\hline Outcome & \\
Success & $75 \%$ \\
Failure & $25 \%$ \\
New Mitral regurgitation or & \\
increased grade & $10 \%$ \\
Patients with Significant & \\
increase" $\geq 2+$ "Mitral & \\
regurgitation & $2.5 \%$ \\
\hline
\end{tabular}

Table 4. Technical failures and Complications related to percutaneous balloon mitral valvuloplasty.

\begin{tabular}{lll}
\hline Complication & $(\mathrm{n})$ & $\%$ \\
\hline Technical failure & 2 & $5 \%$ \\
Vasovagal reaction & 2 & $5 \%$ \\
Prolonged hypotension & 1 & $2.5 \%$ \\
Arrhythmias requiring treatment & 1 & $2.5 \%$ \\
Balloon rupture, no sequaele & 0 & $0 \%$ \\
Bleeding from RT femoral vein & 2 & $5 \%$ \\
Significant hematoma & 1 & $2.5 \%$ \\
Mitral regurgitation & 4 & $10 \%$ \\
Severe mitral regurgitation & 1 & $2.5 \%$ \\
Atrial septal defect & 0 & $0 \%$ \\
Cardiac tamponade & 0 & $0 \%$ \\
Thromboembolism & 0 & $0 \%$ \\
Death & 0 & $0 \%$ \\
\hline
\end{tabular}

derwent redo PBMV or had previous surgical commissurotomy (Table 5). Significant mitral regurgitation was non-significantly associated with a higher Wilkin's score. However, upon further analysis of Wilkin's score parameters, we found that calcification, especially commissural calcification, and higher subvalvular involvement were significantly associated with significant mitral regurgitation ( $p<0.0001$; Table 5 and Figure 1).

\section{Post-Operative Outcomes}

We defined significant symptomatic improvement as an improvement by one or more NYHA functional classifications achieved by 1-month follow-up. We observed a significant change in NYHA functional classification from $2.56 \pm 0.58$ pre-PBMV to $1.09 \pm 0.29$ post-PBMV $(p<0.0001)$. One patient changed from class IV to II, 10 patients changed from class III to I, 10 patients changed from class II to I, and 15 patients changed from class III to II.
Table 5. Factor affecting occurrence of significant Mitral regurgitation (SMR).

\begin{tabular}{|c|c|c|c|}
\hline \multirow[b]{2}{*}{ Features } & \multicolumn{2}{|c|}{$\begin{array}{l}\text { Significant }(\geq+2) \text { increase or } \\
\text { new SMR }\end{array}$} & \multirow[b]{2}{*}{$P$ value } \\
\hline & No & Yes & \\
\hline $\begin{array}{l}\text { Gender } \\
\text { Females } \\
\text { Males }\end{array}$ & $\begin{array}{l}(80.69 \%) \\
(91.31 \%)\end{array}$ & $\begin{array}{l}(55.56 \%) \\
(44.44 \%)\end{array}$ & 0.03 \\
\hline Height & $162.28 \pm 8.13$ & $165.14 \pm 7.01$ & 0.16 \\
\hline L A diameter & $5.01 \pm 0.49$ & $5.12 \pm 0.84$ & 0.41 \\
\hline $\begin{array}{l}\text { Rhythm } \\
\text { Sinus } \\
\text { Atrial fibrillation (AF) }\end{array}$ & $\begin{array}{l}(77.9 \%) \\
(22.1 \%)\end{array}$ & $\begin{array}{l}(27.7 \%) \\
(72.3 \%)\end{array}$ & $<0.0001$ \\
\hline $\begin{array}{l}\text { Previous BMV/ } \\
\text { surgery } \\
\text { No } \\
\text { Yes }\end{array}$ & $\begin{array}{l}(88.97 \%) \\
(11.03 \%)\end{array}$ & $\begin{array}{l}(66.67 \%) \\
(33.33 \%)\end{array}$ & 0.02 \\
\hline $\begin{array}{l}\text { W.S. Thickness } \\
1 \\
2 \\
3\end{array}$ & $\begin{array}{l}(21.38 \%) \\
(55.17 \%) \\
(23.45 \%)\end{array}$ & $\begin{array}{l}(16.67 \%) \\
(50.00 \%) \\
(33.33 \%)\end{array}$ & 0.64 \\
\hline $\begin{array}{l}\text { W.S. Mobility } \\
1 \\
2 \\
3\end{array}$ & $\begin{array}{l}(27.59 \%) \\
(64.14 \%) \\
(8.28 \%)\end{array}$ & $\begin{array}{l}(16.67 \%) \\
(66.67 \%) \\
(16.67 \%)\end{array}$ & 0.37 \\
\hline $\begin{array}{l}\text { W.S. Subvalvular } \\
1 \\
2 \\
3 \\
4\end{array}$ & $\begin{array}{l}(18.6 \%) \\
(69 \%) \\
(11.7 \%) \\
(0.06 \%)\end{array}$ & $\begin{array}{l}(22.2 \%) \\
(16.7 \%) \\
(55.5 \%) \\
(5.6 \%)\end{array}$ & $<0.0001$ \\
\hline $\begin{array}{l}\text { W.S. Calcification } \\
1 \\
2 \\
3 \\
4\end{array}$ & $\begin{array}{l}(22.7 \%) \\
(56.5 \%) \\
(19.3 \%) \\
(1.5 \%)\end{array}$ & $\begin{array}{l}(11.1 \%) \\
(22.3 \%) \\
(33.3 \%) \\
(33.3 \%)\end{array}$ & $<0.0001$ \\
\hline Pre-operative MVA & $0.96 \pm 0.18$ & $0.90 \pm 0.13$ & 0.17 \\
\hline Pre-operative PG & $26.34 \pm 5.34$ & $25.00 \pm 4.32$ & 0.31 \\
\hline Pre-operative PASP & $52.95 \pm 14.06$ & $51.00 \pm 11.07$ & 0.57 \\
\hline
\end{tabular}

$L A=$ Left Atrial; W.S. = Wilkins score; BMV = balloon mitral valvotomy; MVA $=$ mitral valve areas; $\mathrm{PG}=$ prostaglandin; $\mathrm{PASP}=$ pulmonary artery systolic pressure.

Of the 10 patients with chronic atrial fibrillation, one reverted spontaneously to regular sinus rhythm after successful PBMV.

The primary end-point of procedural success commonly accepted by investigators is a final valve area $>1.5 \mathrm{~cm}^{2}$ without moderate or severe mitral regurgitation. We found that mitral valve area as assessed by planimetry increased significantly in all patients after valvuloplasty. The mean valve area was 0.96 
Table 6. Hemodynamic and echocardiographic data of studied population.

Hemodynamic and echocardiographic data

Mean (SD)

P1

MVA

Pre PBMV

$0.96(0.18)$

Post PBMV

$1.93(0.29)$

$<0.0001$

The transverse diameter of the mitral valve

Pre PBMV

$1.54(0.37)$

Post PBMV

$2.43(0.96)$

$<0.0001$

The anteroposterior diameter of the Mitral valve

Pre PBMV

$0.75(0.25)$

Post PBMV

$0.93(0.20)$

$<0.0001$

Mean transmitral Pressure gradient

\begin{tabular}{lll} 
Pre PBMV & $13.26(5.27)$ & \\
Post PBMV & $5.53(3.15)$ & $<0.0001$ \\
Left atrial size & 0 & $0 \%$ \\
Pre PBMV & $4.8(0.7)$ & \\
Post PBMV & $4.2(0.6)$ & $<0.0001$ \\
PASP & & \\
Pre PBMV & $52.83(13.85)$ & \\
Post PBMV & $29.15(8.94)$ & $<0.0001$ \\
Mitral regurgitation & & \\
Pre PBMV & & \\
Post PBMV & $0.91(0.54)$ & \\
\hline
\end{tabular}

PBMV = Percutaneous Balloon Mitral Valvuloplasty; MVA = mitral valve areas; PASP = pulmonary artery systolic pressure.

$\pm 0.18 \mathrm{~cm}^{2}$ before valvuloplasty and $1.93 \pm 0.29 \mathrm{~cm}^{2}$ after valvuloplasty ( $p<0.0001 ;$ Table 6$)$. The transverse diameter of the mitral valve was $1.54 \pm 0.37 \mathrm{~cm}$ before valvuloplasty and 2.43 $\pm 0.96 \mathrm{~cm}$ after valvuloplasty $(p<0.0001)$. Also, trans-mitral diastolic mean pressure gradient decreased from $13.26 \pm 5.27$ $\mathrm{mm} \mathrm{Hg}$ before valvuloplasty to $5.53 \pm 3.15 \mathrm{~mm} \mathrm{Hg}$ after valvuloplasty $(p<0.0001)$.

Pulmonary hypertension frequently complicates mitral stenosis and may significantly influence clinical findings and prognosis. The increase in pulmonary arterial pressure is often out of proportion to the degree of left atrial hypertension, which reflects a major increase in pulmonary vascular resistance [28]. In the present study, the average pulmonary artery systolic pressure decreased significantly after 1 month from $52.83 \pm 13.85 \mathrm{~mm} \mathrm{Hg}$ to $29.15 \pm 8.94 \mathrm{~mm} \mathrm{Hg}(p<0.0001)$.

At 1-month follow-up, the left atrium anteroposterior dimension decreased in $85 \%$ of patients (from $4.8 \pm 0.7 \mathrm{~cm}$ to
Table 7. Factor affecting occurrence of significant Mitral regurgitation (SMR).

\begin{tabular}{|c|c|c|c|}
\hline \multirow[b]{2}{*}{ Features } & \multicolumn{2}{|l|}{ Outcome } & \multirow[b]{2}{*}{$P$ value } \\
\hline & Failure & Success & \\
\hline $\begin{array}{l}\text { Gender } \\
\text { Females } \\
\text { Males }\end{array}$ & $\begin{array}{l}(50.00 \%) \\
(50.00 \%)\end{array}$ & $\begin{array}{l}(86.87 \%) \\
(13.13 \%)\end{array}$ & 0.01 \\
\hline Height & $166 \pm 7.76$ & $157.24 \pm 8.25$ & 0.002 \\
\hline L A diameter & $4.88 \pm 0.83$ & $4.60 \pm 0.49$ & 0.11 \\
\hline $\begin{array}{l}\text { Rhythm } \\
\text { Sinus } \\
\text { Atrial fibrillation (AF) }\end{array}$ & $\begin{array}{l}(30.00 \%) \\
(70.00 \%)\end{array}$ & $\begin{array}{l}(88.89 \%) \\
(11.11 \%)\end{array}$ & $<0.0001$ \\
\hline $\begin{array}{l}\text { Previous BMV/ } \\
\text { surgery } \\
\text { No } \\
\text { Yes }\end{array}$ & $\begin{array}{l}(90.00 \%) \\
(10.00 \%)\end{array}$ & $\begin{array}{l}(89.90 \%) \\
(10.10 \%)\end{array}$ & 0.99 \\
\hline $\begin{array}{l}\text { W.S. Thickness } \\
1 \\
2 \\
3\end{array}$ & $\begin{array}{l}(20.00 \%) \\
(70.00 \%) \\
(10.00 \%)\end{array}$ & $\begin{array}{l}(29.29 \%) \\
(58.59 \%) \\
(12.12 \%)\end{array}$ & 0.78 \\
\hline $\begin{array}{l}\text { W.S. Mobility } \\
1 \\
2 \\
3\end{array}$ & $\begin{array}{l}(20.00 \%) \\
(70.00 \%) \\
(10.00 \%)\end{array}$ & $\begin{array}{l}(36.36 \%) \\
(60.61 \%) \\
(3.03 \%)\end{array}$ & 0.36 \\
\hline $\begin{array}{l}\text { W.S. Subvalvular } \\
1 \\
2 \\
3\end{array}$ & $\begin{array}{l}(30.00 \%) \\
(40.00 \%) \\
(30.00 \%)\end{array}$ & $\begin{array}{l}(71.72 \%) \\
(23.23 \%) \\
(5.05 \%)\end{array}$ & 0.01 \\
\hline $\begin{array}{l}\text { W.S. Calcification } \\
1 \\
2 \\
3\end{array}$ & $\begin{array}{l}(30.00 \%) \\
(40.00 \%) \\
(30.00 \%)\end{array}$ & $\begin{array}{l}(62.63 \%) \\
(30.30 \%) \\
(7.07 \%)\end{array}$ & 0.051 \\
\hline Pre-operative MVA & $1.03 \pm 0.18$ & $0.96 \pm 0.18$ & 0.22 \\
\hline Pre-operative PG & $24.1 \pm 4.07$ & $26.47 \pm 5.36$ & 0.18 \\
\hline Pre-operative PASP & $52.2 \pm 13.82$ & $52.89 \pm 13.92$ & 0.88 \\
\hline
\end{tabular}

$\mathrm{L} A=$ Left Atrial; W.S. = Wilkins score; BMV = balloon mitral valvotomy; MVA $=$ mitral valve areas; $P G=$ prostaglandin; $P A S P=$ pulmonary artery systolic pressure.

$4.2 \pm 0.6 \mathrm{~cm} ; p<0.0001)$ and remained unchanged in $15 \%$ of patients.

\section{Factors Influencing Procedural Success}

Total echocardiographic score was the strongest predictor of procedural success, with lower scores associated with a greater likelihood of a successful outcome (Table 7). Of the different components of Wilkin's score, the presence of subvalvular disease and calcification were most strongly associated with success rate, whereas valvular thickening and mobility were most strongly associated with dilatation. 


\section{Discussion}

Despite a dramatic decline in the incidence of rheumatic fever, the disease continues to affect many people [7]. Balloon mitral valvotomy, which was first performed in 1982 by Kanji Inoue in Japan, produces excellent results equivalent to those obtained with open or closed surgical valvotomy. In countries with a high prevalence of rheumatic heart disease, such as Egypt, mitral stenosis is a common presentation, and PBMV is a particularly valuable treatment modality. Here, utilizing a prospective, single-center study design, we describe the outcomes of PBMV for elderly patients with mitral stenosis, including those with high Wilkin's scores, relative contraindications, and refusal of valve replacement.

In earlier studies, percutaneous balloon commissurotomy was used in patients with pliable noncalcified mitral valves [2], while more recent studies report the efficacy of balloon commissurotomy even in calcific disease $(70 \%$ of our patients had Wilkin's scores of 9 or 10) [9]. The results of the present study confirm those of a previous multicenter trial by Inoue et al. [5], which showed that PBMV using the Inoue balloon catheter technique significantly increases mitral valve area in patients with severe mitral stenosis. In association with an increased valve area, we observed significantly reduced mitral valve gradient, left atrial pressure and size, and mean pulmonary artery systolic pressure. These hemodynamic benefits were mirrored by clinical improvements in patients' symptoms and significant downgrades in NYHA functional classification. Therefore, consistent with previous studies $[6,7,10,11,12]$, our results show that PBMV produces immediate hemodynamic and clinical improvements in most patients.

In our experience, PBMV has a high technical success rate and an encouraging safety record. In the present study, trans-septal catheterization was successful and uncomplicated, and there was no in-hospital mortality. These results are comparable to those from Palacios et al., who reported only one death (3\%) and one thromboembolic episode (3\%) after valvuloplasty [13]. McKay et al. also reported only one death (2\%) and two embolic cerebrovascular accidents (3\%) in a large series involving 63 patients, speculating that their success was due to the nature of the Inoue balloon, especially its flow-directed pas-

Journal of Structural Heart Disease, April 2017 sage from the left atrium to the left ventricle [9]. In the present study, an Inoue balloon also achieved a smooth delivery in most patients.

An increase in mitral regurgitation is one possible complication after percutaneous balloon commissurotomy. However, in most cases, the degree of mitral regurgitation slightly increases after PBMV without requiring surgical intervention. The mechanism of the increase or new appearance of mitral regurgitation is reported to be excessive tearing of the commissures(s) or the posterior/anterior leaflet at the noncommissural part, incomplete closure of a calcified leaflet, localized rupture of the subvalvular apparatus, or shortened chordate tendineae after splitting of the commissure(s). Although the incidence of mitral regurgitation has slightly decreased in the past few years, the appearance or worsening of mitral regurgitation after balloon mitral valvotomy is still a major concern $[14,15,16,17,18]$. Although approximately half of patients undergoing balloon mitral valvotomy exhibit a small increase in mitral regurgitation $[19,20]$, severe mitral regurgitation is relatively rare, with a frequency ranging from 1.4 to $9.4 \%[13,21]$. There are even some reports of a decrease in mitral regurgitation after balloon mitral valvotomy $[22,23,24]$. In the present study, we observed no change in mitral regurgitation in the majority of patients and severe mitral regurgitation ( $\geq 3$ grade) in only one patient $(2.5 \%)$.

We found that elderly patients with a higher calcification score and more subvalvular involvement were more likely to exhibit an increase in mitral regurgitation, whereas total Wilkin's score did not predict the occurrence of mitral regurgitation. This is consistent with the finding of Aslanabadi et al. that calcification is the most important component of Wilkin's classification in that it can predict mitral regurgitation [25]. By contrast, others reported that an increase in mitral regurgitation is not predicted by any valvular or subvalvular apparatus features, patient clinical characteristics, or technical aspects of the procedure $[26,27]$.

\section{Limitations}

Our study has several limitations. The study was performed at a single center with a relatively small sample size, which limits the generalizability of the results to all patients with mitral stenosis. Therefore, multicenter 
studies using the same protocol with a larger number of patients are needed. Because all of our patients underwent PBMV with the Inoue balloon technique, it is unknown whether our data can be safely extrapolated to patients undergoing double-balloon PBMV or percutaneous metallic valvotomy. Furthermore, we depended only on Wilkin's score to assess mitral stenosis, which has several limitations, including a limited ability to differentiate nodular fibrosis from calcification, an inability to account for uneven distribution of pathological abnormalities, an inability to assess commissural involvement, and frequent underestimation of subvalvular disease.

\section{Conclusions}

Elderly patients with rheumatic heart disease and mitral stenosis show a tendency toward a higher degree of calcification and fibrosis of the mitral valve. This may be attributed to a greater likelihood of repeated episodes of active rheumatic disease, which highlights the importance of administering rheumatic fever prophylaxis to younger patients undergoing PBMV procedures. Our study confirmed that PBMV is a safe and effective procedure that can be used for those with less favorable valve morphology. Without questioning the value of Wilkin's score or its cut-off point, our study shows that successful PBMV can be accomplished in patients with a Wilkin's score between 9 and 10. In conclusion, PBMV and redo PBMV can be employed as a palliative technique in patients with mitral regurgitation at a high risk of morbidity and mortality due to the presence of significant comorbid disease.

\section{Conflict of Interest}

The authors have no conflict of interest relevant to this publication.

\section{Comment on this Article or Ask a Question}

\section{References}

1. Rossi EG, Cardoso LF, Ávila WS, Grinberg M. Estenose mitral em assintomáticos. Rev Soc Cardiol Estado de São Paulo. 1997;7:741-746.

2. Bruce CJ, Nishimura RA. Newer advances in the diagnosis and treatment of mitral stenosis. Curr Probl Cardiol. 1998;23: 125-129. DOI: 10.1016/S01462806(98)80004-2

3. Carroll JD, Feldman T. Percutaneous mitral valvotomy and the new demographics of mitral stenosis. JAMA. 1993;270: 1731-1736. DOI: 10.1001/ jama.1993.03510140091035

4. Strasser T, Dondog N, El Kholy A, Gharagozlo $R$, Kalbian VV, Ogunbi O, et al. The community control of rheumatic fever and rheumatic heart disease: Report of a WHO international cooperative project. Bull World Health Organ. 1981;59:285-294. PMID: 6972819

5. Inoue K, Owaki T, Nakamura T, Kitamura F, Miyamoto N. Clinical application of transvenous mitral commissurotomy by a new balloon catheter. J Thorac Cardiovasc Surg. 1984;87:394-402. PMID: 6700245

6. Wilkins GT, Weyman AE, Abascal VM, Block PC, Palacios IF. Percutaneous balloon dilatation of the mitral valve: An analysis of echocardiographic variables related to outcome and the mechanism of dilatation. Br Heart J. 1988;60:299-308. DOI: 10.1136/hrt.60.4.299

7. Sanati HR, Kiavar M, Salehi N, Shakeria F. Percutaneous mitral valvuloplasty-A new method for balloon sizing based on maximal commissural diameter to improve procedural results. Amer Heart Hosp J. 2010;8:29-32. DOI: 10.15420/ ahhj.2010.8.1.29

8. Zaibag MA, Kasab SA, Ribeiro PA, Fagih MR. Percutaneous double balloon mitral valvotomy for rheumatic mitral valve stenosis. Lancet. 1986;327:757-761. DOI: 10.1016/ S0140-6736(86)91780-0

9. McKay RG, Lock JE, Safian RD, Come PC, Diver DJ, Baim DS, et al. Balloon dilation of mitral stenosis in adult patients: Postmortem and percutaneous mitral valvuloplasty studies. J Am Coll Cardiol. 1987;9:723731. DOI: 10.1016/S0735-1097(87)80224-3

10. Inoue K, Hung JS. Percutaneous transvenous mitral commissurotomy (PTMC): The far east experience. In: Topol EJ (ed.). Textbook of Interventional Cardiology. Philadelphia, PA:WB Saunder; 1990, p. 887-899.

11. Fawzy ME, Mimesh L, Sivanandam V, Lingamanaicker J, Al-Amiri M, Khan B. Advantage of Inoue balloon catheter in mitral balloon valvotomy: Experience with 220 consecutive patients. Cathet Cardiovasc Diagn. 1996;38:9-14. DOI: 10.1002/ (SICI) 1097-0304(199605)38:1<9::AIDCCD3>3.0.CO;2-E

12. Essop MR, Nkomo VT. Rheumatic and nonrheumatic valvular heart disease: Epidemiology, management, and prevention in Af- rica. Circulation. 2005;112:3584-3591. DOI: 10.1161/CIRCULATIONAHA.105.539775

13. Palacios IF, Sanchez PL, Harrell LC, Weyman $A E$, Block PC. Which patients benefit from percutaneous mitral balloon valvuloplasty? Prevalvuloplasty and postvalvuloplasty variables that predict long-term outcome. Circulation. 2002;105:1465-1471. DOI: 10.1161/01.CIR.0000012143.27196.F4

14. Roth RB, Block PC, Palacios IF. Predictors of increased mitral regurgitation after percutaneous mitral balloon valvotomy. Cathet Cardiovasc Diagn. 1990;20:17-21. DOI: 10.1002/ ccd.1810200105

15. Arora R, Kalra GS, Murty GSR, Trehan V, Jolly $\mathrm{N}$, Mohan JC, et al. Percutaneous transatrial mitral commissurotomy: Immediate and intermediate results. J Am Coll Cardiol. 1994;23:1327-1332. DOI: 10.1016/07351097(94)90374-3

16. Kaul UA, Singh S, Kalra GS, Nair M, Mohan $J C$, Nigam $M$, et al. Mitral regurgitation following percutaneous transvenous mitral commissurotomy: A single-center experience. J Heart Valve Dis. 2000;9:262-266. PMID: 10772045

17. Dighero $H$, Zepeda $F$, Sepúlveda $P$, Soto JR, Aranda W. Percutaneous mitral balloon valvotomy: Six-year follow-up. J Invasive Cardiol. 2001;13:795-799. PMID: 11731691

18. Fawzy ME, Shoukri M, Al Buraiki J, Hassan W, El Widaal H, Kharabsheh S, et al. Seven- 
teen years' clinical and echocardiographic follow up of mitral balloon valvuloplasty in 520 patients, and predictors of long-term outcome. J Heart Valve Dis. 2007;16:454460. PMID: 17944115

19. Palacios I, Block PC, Brandi S. Percutaneous ballon valvulotomy for patients with severe stenosis. Circulation. 1987;75:778784. DOI: 10.1161/01.CIR.75.4.778

20. Herrmann HC, Wilkins GT, Abascal VM, Weyman AE, Block PC, Palacios IF. Percutaneous balloon valvotomy for patients with mitral stenosis: Analysis of factors influencing early results. J Thorac Cardiovasc Surg. 1988;96:33-38. PMID: 3386292

21. Chen CR, Cheng TO, Chen JY. Long-term results of percutaneous balloon mitral valvuloplasty for mitral stenosis. Cathet Cardiovasc Diagn. 1998;43:132-139. DOI: 10.1002/ (SICI) 1097-0304(199802)43:2<132::AIDCCD5 > 3.0.CO;2-B

22. Palacios IF, Block PC, Wilkins GT, Weyman $A E$. Follow-up of patients undergoing percutaneous mitral balloon valvotomy. Analysis of factors determining restenosis. Circulation. 1989;79:573-579. DOI: 10.1161/01.CIR.79.3.573

23. Vahanian $A$, Michel PL, Cormier B, Vitoux $B$, Michel X, Slama M, et al. Results of percutaneous mitral commissurotomy in 200 patients. Am J Cardiol. 1989;63:847852. DOI: $10.1016 / 0002-9149(89) 90055-6$

24. Sadeghian $H$, Salarifar M, Rezvanfard $M$, Nematipour E, Lotfi-Tokaldany $M$, Safir Mardanloo A, et al. Percutaneous transvenous mitral commissurotomy: Significance of echocardiographic assessment in prediction of immediate result. Arch Iran Med. 2012;15:629-634. DOI: 0121510/AIM.0010

25. Aslanabadi N, Jamshidi P, Gaffari S, Ayatollahi Z, Kazemi B, Javadzadeghan $\mathrm{H}$. Clinical symptoms of mitral stenosis therapy in men and women. J KUMS. 2007;10: 311-319.

26. Abascal VM, Wilkins GT, Choong CY, Block PC, Palacios IF, Weyman AE. Mitral regur- gitation after percutaneous balloon mitral valvuloplasty in adults: Evaluation by pulsed Doppler echocardiography. J Am Coll Cardiol. 1988;11:257-263. DOI: 10.1016/0735-1097(88)90089-7

27. Pan M, Medina A, de Lezo JS, Hernandez E, Romero M, Pavlovic D, et al. Factors determining late success after mitral balloon valvulotomy. Am J Cardiol. 1993;71:11811186. DOI: 10.1016/0002-9149(93)90643-Q

28. Yen-Chun Lai, Karin C. Potoka, Hunter C. Champion, Ana L. Mora, Mark T. Gladwin. Pulmonary Arterial Hypertension: The Clinical Syndrome. Circ Res. 2014:115: 115-130. DOI: 10.1161/CIRCRESAHA.115.301146

Cite this article as: Mahmoud SES, Abodahab LH, Bahaa M. Percutaneous Balloon Mitral Valvuloplasty in the Elderly. 2017;3(2):35-42. DOI: http:// dx.doi.org/10.12945/j.jshd.2017.011.16 